\title{
Some nematodes of the genus Rhabdias Stiles et Hassall, 1905 (Nematoda: Rhabdiasidae) parasitising amphibians in French Guiana
}

\author{
Yuriy Kuzmin ${ }^{1}$, Louis H. du Preez ${ }^{2}$ and Kerstin Junker ${ }^{3}$ \\ ${ }^{1}$ Department of Parasitology, Institute of Zoology, Kyiv, Ukraine; \\ ${ }^{2}$ Unit for Environmental Sciences and Management, North-West University, Potchefstroom, South Africa; \\ ${ }^{3}$ Agricultural Research Council-Onderstepoort Veterinary Institute, Onderstepoort, South Africa
}

\begin{abstract}
Based on material collected from Rhinella cf. margaritifera (Laurenti) and Rhi. marina (Linnaeus) (Anura: Bufonidae) during a parasite survey of the herpetofauna of French Guiana, updated descriptions of Rhabdias androgyna Kloss, 1971 and R. fuelleborni Travassos, 1926 are presented. In addition to metrical data, which may overlap in closely related species, emphasis is placed on qualitative characters. Rhabdias androgyna is distinguished by the unique presence of an outer and inner cephalic cuticular inflation, a shoulder-like broadening of the body at the anterior end, a wide and shallow buccal capsule (average buccal ratio 0.36) with serrated lumen in apical view, a prominent anterior dilatation of the oesophagus, and the presence of an additional posterior dilatation anterior to the oesophageal bulb. Characters that may help to differentiate $R$. fuelleborni from closely related species parasitising the Rhi. marina species group are the presence of six relatively uniform lips, and the division of the buccal capsule into an anterior and posterior segment, with differently structured walls. Both the presence of $R$. androgyna and R. fuelleborni in French Guiana constitute new geographic records. A single specimen of Rhabdias sp. is described from Pristimantis chiastonotus (Lynch et Hoegmood) (Anura: Craugastoridae). This species differs from all its Neotropical congeners by the distinct globular swelling of its head, similar to that seen in only one Palaearctic and one Afrotropical Rhabdias species. A list of species of Rhabdias parasitising amphibians in the Netropical Realm is also provided.
\end{abstract}

Keywords: Rhabdias androgyna, Rhabdias fuelleborni, Rhinella, Pristimantis, morphology, Neotropical Realm, new geographical records

Nematodes of the genus Rhabdias Stiles et Hassall, 1905 are lung-dwelling parasites of amphibians and, to some extent, reptiles. The genus has a world-wide distribution and comprises more than 70 nominal species (Kuzmin and Tkach 2014). Together with most other rhabdiasids, members of this genus share a heterogonic life cycle, in which a parasitic hermaphroditic generation and a free-living generation of males and females alternate (Anderson 2000, Kuzmin 2013, Tkach et al. 2014). No less than 18 species of Rhabdias occur in the Neotropical Realm, 15 of which are parasitic in amphibians. Most species are known from their first descriptions only, and their exact geographic distribution and host range are still to be investigated. Especially descriptions dating back into the $20^{\text {th }}$ century often lack morphological detail, rendering comparison with more recently collected materials difficult. However, in order to be able to study the phylogenetic relationships between the Neotropical species of Rhabdias themselves as well as with their congeners worldwide, detailed knowledge about their host spectrum, geographic range as well as morphology is imperative.
Of the 15 nominal species parasitising amphibians in the Neotropical Realm, two of which are considered species inquirendae, nine species have been reported from the northern parts of the Neotropics (Mexico and Central America) and six species occur in South America only (see below). During a brief herpetological and helminthological survey of amphibians and reptiles in French Guiana in April 2012, the lungs and other organs of collected hosts were screened for parasites. Three distinct nematode species belonging to Rhabdias were found in the lungs of the three anurans, Rhinella $\mathrm{cf}$. margaritifera (Laurenti), Rhi. marina (Linnaeus) (Bufonidae), and Pristimantis chiastonotus (Lynch et Hoogmoed) (Craugastoridae). The specimens from Rhi. cf. margaritifera were identified as $R$. androgyna Kloss, 1971. This species was originally described based on three specimens from Brazil (Kloss 1971), and no further descriptions of the species have been published since. In order to augment the somewhat perfunctory original description, we examined the recently collected material and give a detailed description of their

Address for correspondence: K. Junker, Agricultural Research Council-Onderstepoort Veterinary Institute, Private Bag X05, Onderstepoort 0110, South Africa. Phone: +27 12529 9215; Fax: +27 12529 9434; E-mail: junkerk@arc.agric.za 
morphology. The nematodes from Rhi. marina were identified as $R$. fuelleborni Travassos, 1926, though by some characters they were closer to $R$. elegans Gutiérrez, 1945, emphasising the need for updated morphological studies. The description of the gravid individuals recovered from Rhi. marina is presented below. One nematode found in the lungs of $P$. chiastonotus clearly differed from all Rhabdias spp. known in the Neotropics. As it further illustrates the diversity of Rhabidas in the Neotropical Realm, we present the description of this single specimen, concluding that it belongs to a new species of Rhabdias that may be named and formally described in future, once additional material is available.

\section{MATERIALS AND METHODS}

In April 2012, nine Rhinella cf margaritifera and a single specimen each of Rhi. marina and Pr. chiastonotum were collected in French Guiana as part of an unrelated study and examined for parasites by one of the authors (L.H.duP.). Hosts are stored in the collection of L.H.duP., North-West University: Rhi. cf margaritifera (field no. AL120416A1, AL120418D1-2, AL120419A1-3); Rhi. marina (field no. AL120410D1); Pr. chiastonotus (field no. AL120417I1). In future, it may thus be possible to ascertain the precise identity of hosts currently assigned to the Rhi. cf margaritifera species complex.

Helminths collected from the lungs were fixed in hot $70 \%$ ethanol and subsequently stored in $70 \%$ ethanol. For identification and morphological studies, specimens were temporarily mounted in lactophenol and examined under a Zeiss Axio Imager M1 microscope with differential interference contrast and equipped with a digital camera. Measurements were taken with the aid of digital imaging software (Zeiss AxioVision40 version 4.6.3), and line drawings were made based on single or series of digital images. All measurements are given in micrometres unless otherwise stated. Body widths were measured excluding the cuticular inflation. The classification of amphibian hosts follows that of Frost (2014) and Fouquet et al. (2007), that of reptilian hosts Uetz and Hošek (2015).

\section{RESULTS}

Rhabdiasidae Railliet, 1915

Genus Rhabdias Stiles et Hassal, 1905

Rhabdias androgyna Kloss, 1971

Figs. 1, 2

Morphological description (based on 29 gravid specimens; measurements are given as the range followed by the mean in parentheses): Medium sized, slender worms, 7.9-15.4 mm (11.9 mm) long, 200-294 (250) wide at oesophago-intestinal junction, 269-473 (371) wide at vulva. Body of relatively uniform width throughout most of its length, but tapering anteriorly from level of oesophagointestinal junction onwards; posterior end tapering slightly at short distance anterior to anus, but with rapidly narrowing tail (Fig. 2A).

Body cuticle irregularly inflated along entire body, inflation more pronounced in cephalic and tail regions (Figs. 1A,G, 2A,D). Cephalic inflation divided into usu- ally distinctly rounded outer and inner layers (Figs. 1A, 2D). Maximum width of outer cephalic inflation 273-706 (473), of inner inflation 214-335 (269). Inner cephalic inflation terminated at its connection to body wall on level of shoulder-like broadening of body outline. Usually distinct narrowing of outer cephalic inflation seen at this point as well, followed by gradual narrowing of inflation to level of oesophago-intestinal junction from whereon inflation retains more or less constant width with irregular, pronounced folds in some specimens. Caudal cuticular inflation with one large transverse fold prior to anus, and second large fold posterior to anus, reaching midlength of tail and followed by a series of smaller folds, rapidly decreasing in size (Fig. 1G). Posterior portion of tail tip without cuticular inflation. Lateral pores in body wall present, arranged in two lines, one on each side of body. Each pore connected to straight duct crossing inflated part of body cuticle (Fig. 2B).

Prominent dilatation of body present in anterior part at 40-89 (58) from anterior end, shoulder-like in lateral view (Figs. 1A,F). At this point, body 157-225 (194) wide; body width anterior to shoulder-like broadening 141-203 (170). Body wall anterior to shoulder-like broadening with 4 longitudinal elevations on dorsal, ventral and both lateral sides (Fig. 1B); elevations decreasing posteriorly and disappearing at level of shoulder-like broadening.

Oral opening small, round, in most specimens situated at bottom of apical depression of body wall (Figs. 1A, 2D). Depression depth possibly related to fixation. Four larger submedian lips and two smaller lateral lips present (Fig. 1B). Submedian lips projecting slightly into oral opening, narrow and elongate, with one internal labial papilla and two external labial papillae each. On each lip, thin cuticular 'M'-shaped fold present, separating external labial papillae from internal part of lip. Lateral lips situated at larger distance from oral opening, each bearing one internal labial and one minute external labial papilla. Amphidial openings small, rounded, situated at base of lateral lips.

Vestibulum funnel-shaped anteriorly and cylindrical with cuticularised wall posteriorly (Fig. 1C,F). In lateral view this subdivision not always visible, anterior part absent in some specimens; posterior cylindrical part measured in 10 specimens, 9-15 (11) long. Velum absent. Buccal capsule 7-9 (8) long and 19-27 (23) wide, length to width ratio $0.29-0.47(0.36)$, round in apical view, a flattened oval in lateral view, thick-walled with cylindrical lumen; in apical view, inner wall serrated along its length excepting its bottom (Fig. 1D,E); posterior segment absent.

Oesophagus 598-751 (684) long, occupying 4.7-8.0\% $(5.9 \%)$ of total body length, generally club-shaped, its shoulders reaching anterior level of buccal capsule (Fig. 1F). Distinct rounded dilatation present in anterior, muscular part; smaller dilatation halfway between nerve ring and posterior bulb (Figs. 1A, 2D). Width of oesophagus 62-77 (69) at anterior end, 88-111 (100) at muscular dilatation, 54-69 (60) at level of nerve ring. Maximum width of oesophagus at posterior bulb, 108-159 (135).

Nerve ring at 210-300 (254) from anterior end, just posterior to anterior dilatation of oesophagus (Fig. 1A). Excre- 


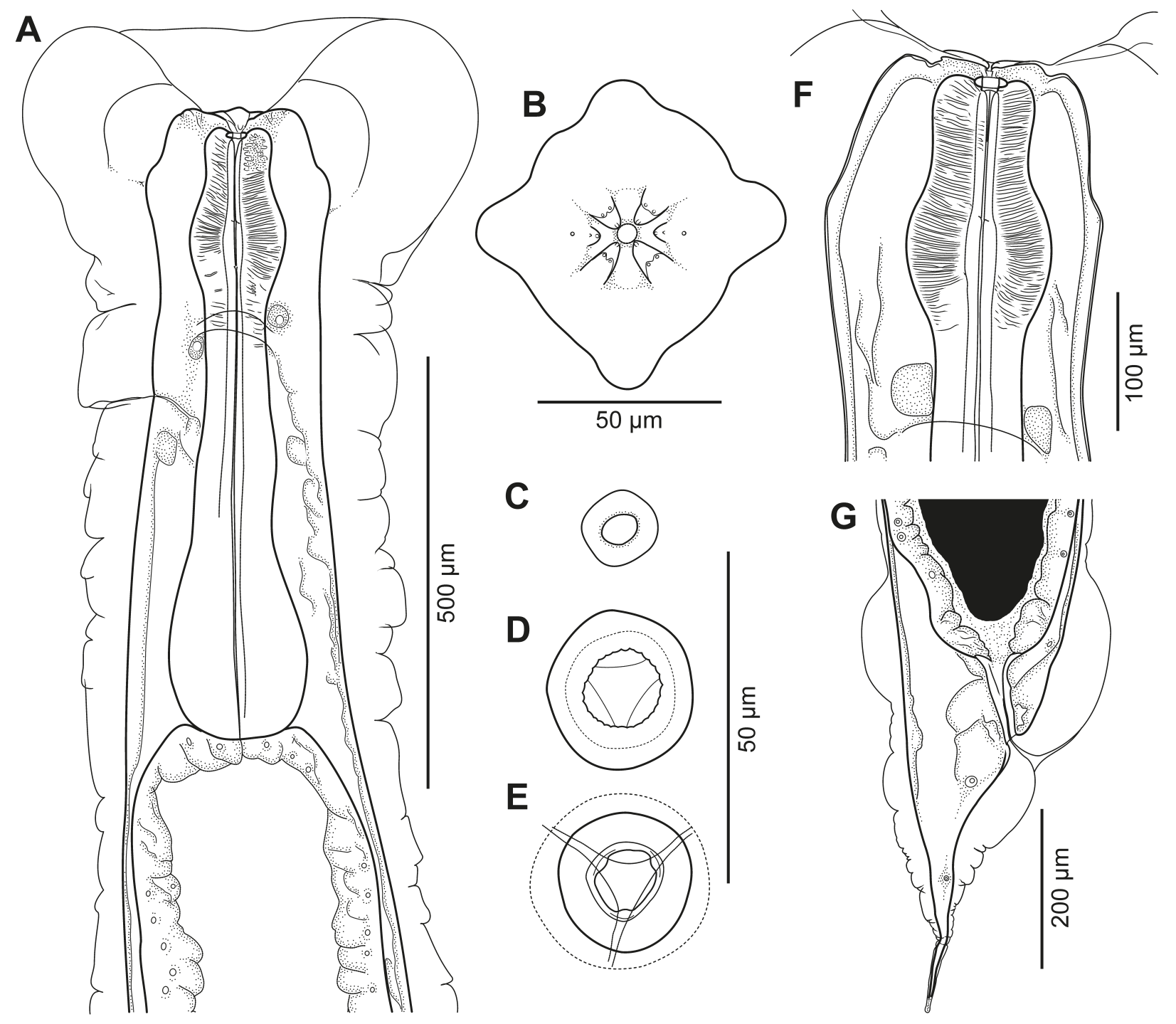

Fig. 1. Rhabdias androgyna Kloss, 1971 from Rhinella cf. margaritifera, line drawings. A - anterior part of body, lateral view; B - anterior extremity, en face view; C - optical section through vestibulum; D - optical section through mid-region of buccal capsule; $\mathbf{E}$ - optical section through bottom of buccal capsule; $\mathbf{F}$ - anterior end, dorsoventral view; $\mathbf{G}$ - caudal part, lateral view.

tory pore situated between level of nerve ring and second slight dilatation of oesophagus (Fig. 1A), at 293-356 (321) from anterior end. Excretory glands not observed in gravid specimens. Intestine thick-walled, in some specimens apex of intestine wider than base of oesophageal bulb, with shallow depression accommodating bulb (Fig. 2D); in other specimens base of oesophageal bulb and apex of intestine equal in size, but intestine widening abruptly at short distance from oesophago-intestinal junction to same width as in former specimens. Contents of intestine reddish to brown in anterior part, darkening to black posteriorly. Rectum straight, slightly dilated anteriorly, with weakly cuticularised walls (Fig. 1G).

Vulva usually just pre-equatorial, in some specimens at mid-length of body, slit-like and slightly salient; situated at $3.7-7.2 \mathrm{~mm}(5.7 \mathrm{~mm})$ from anterior end, i.e. $44.5-50.8 \%$ (47.6\%) of body length. Vagina transverse, short, straight, cuticularised. Uteri amphidelphic, approximately equal, thin-walled, tubular, with eggs arranged in 2-3 rows; majority of eggs near vulva containing first-stage larvae.
Eggs 101-113 × 47-51 (five eggs measured outside uterus in a specimen damaged in region of vulva). Anterior and posterior distal flexure of female genital system at some distance from oesophago-intestinal junction and anus, respectively, situated in oviduct. Distal parts of ovaries and oviducts usually looped and often folded upon themselves. Proximal ends of ovaries overlapping slightly at level of vulva. Testis zone in ovaries (Fig. 2C) observed in some specimens, usually seen in posterior ovary $(n=6)$, but also identified in anterior ovaries $(\mathrm{n}=2)$.

Tail 304-455 (373) long, i.e. 2.4-4.4\% (3.1\%) of body length. A distinct elevation of body wall posterior to anus followed by an abrupt narrowing of tail (Fig. 1G), especially pronounced in larger specimens. Phasmids at 131-180 (163) from tail tip, tip of tail filled with granular material.

Description of one immature specimen from host lungs (Fig. 2E,F). Body smaller and comparatively narrower than in gravid worms; body length $4.2 \mathrm{~mm}$, width at oesophago-intestinal junction 132, width at vulva 150 . Body cuticle less inflated and cephalic inflation less pro- 


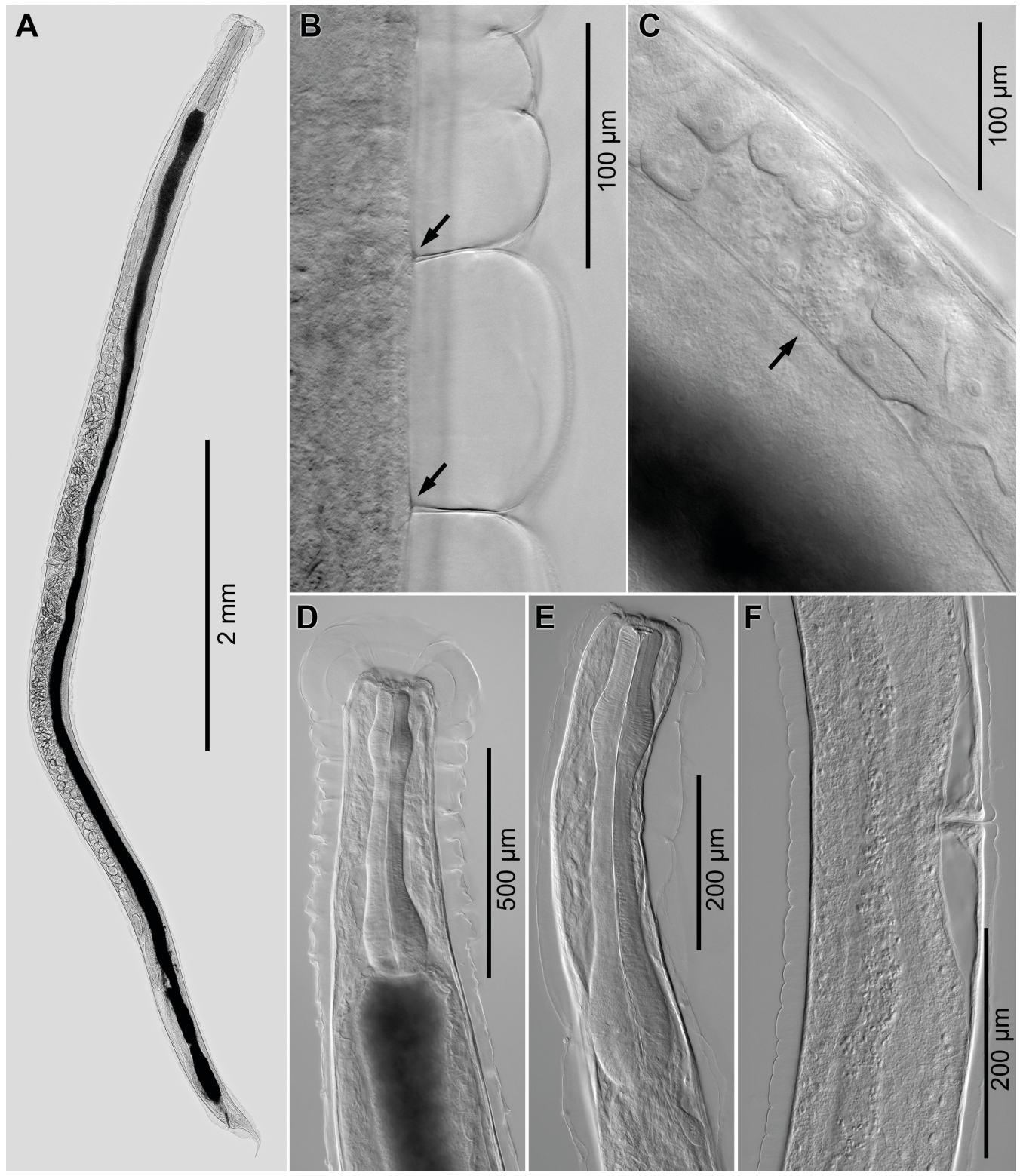

Fig. 2. Rhabdias androgyna Kloss, 1971 from Rhinella cf. margaritifera, photomicrographs. A - general view of gravid specimen; B - section of body wall at level of oesophagus, showing lateral pores (arrows) and ducts; $\mathbf{C}$ - testis zone (arrow) in posterior syngonium; D - anterior part of body, dorsoventral view; E, F - immature specimen: $\mathbf{E}$ - anterior part of body, lateral view; $\mathbf{F}$ - region of vulva, lateral view.

nounced, though division into inner and outer inflations obvious (Fig. 2E); inflations 142 and 164 wide, correspondingly. Shoulder-like broadening of body outline indistinct, anterior part of body wide, truncated (Fig. 2E). Apical depression of body wall absent. Vestibulum 9 deep. Buccal capsule 8 long and 24 wide (ratio 0.33). Oesophagus of same shape as that in gravid individuals, 530 long (12.6\% of body length). Width of oesophagus 49 at apex, 71 at anterior dilatation, 42 at nerve ring; bulb 92 wide. Nerve ring at 184 , and excretory pore at 260 from anterior end. Excretory glands present, their posterior parts pyriform, situated posterior to oesophago-intestinal junction (Fig. 2E). Intestine wide, occupying almost whole inner space of body in anterior and posterior part, with ventral narrowing in region of vagina (Fig. 2F). Contents of intestine granulated, not coloured. Rectum short, conical. Vulva slightly sali- ent, postequatorial, situated at $2.3 \mathrm{~mm}$ from anterior end (54.3\% of body length). Uteri short, empty (Fig. 2F). Other parts of genital system narrow, lacking germinal cells. Tail of same shape as that in gravid individuals, slightly narrower and more elongated, 232 long (5.5\% of body length).

Host: Rhinella cf. margaritifera (Laurenti) (Bufonidae); collected during 9-23 April 2012.

L ocality: Nouragues National Reserve, French Guiana, $04^{\circ} 02^{\prime} 23.5^{\prime \prime} \mathrm{N} ; 52^{\circ} 40^{\prime} 29.2^{\prime \prime} \mathrm{W}$.

Site of infection: Lungs.

Prevalence and intensity of infection: Six of nine hosts infected $(67 \%)$, with a mean intensity of infection of $13(2-25)$.

Deposition of specimens: Seventy-one specimens (S/2014/4-S/2014/8; S/2014/18) deposited in the National Collection of Animal Helminths (NCAH), Agricultural Re- 


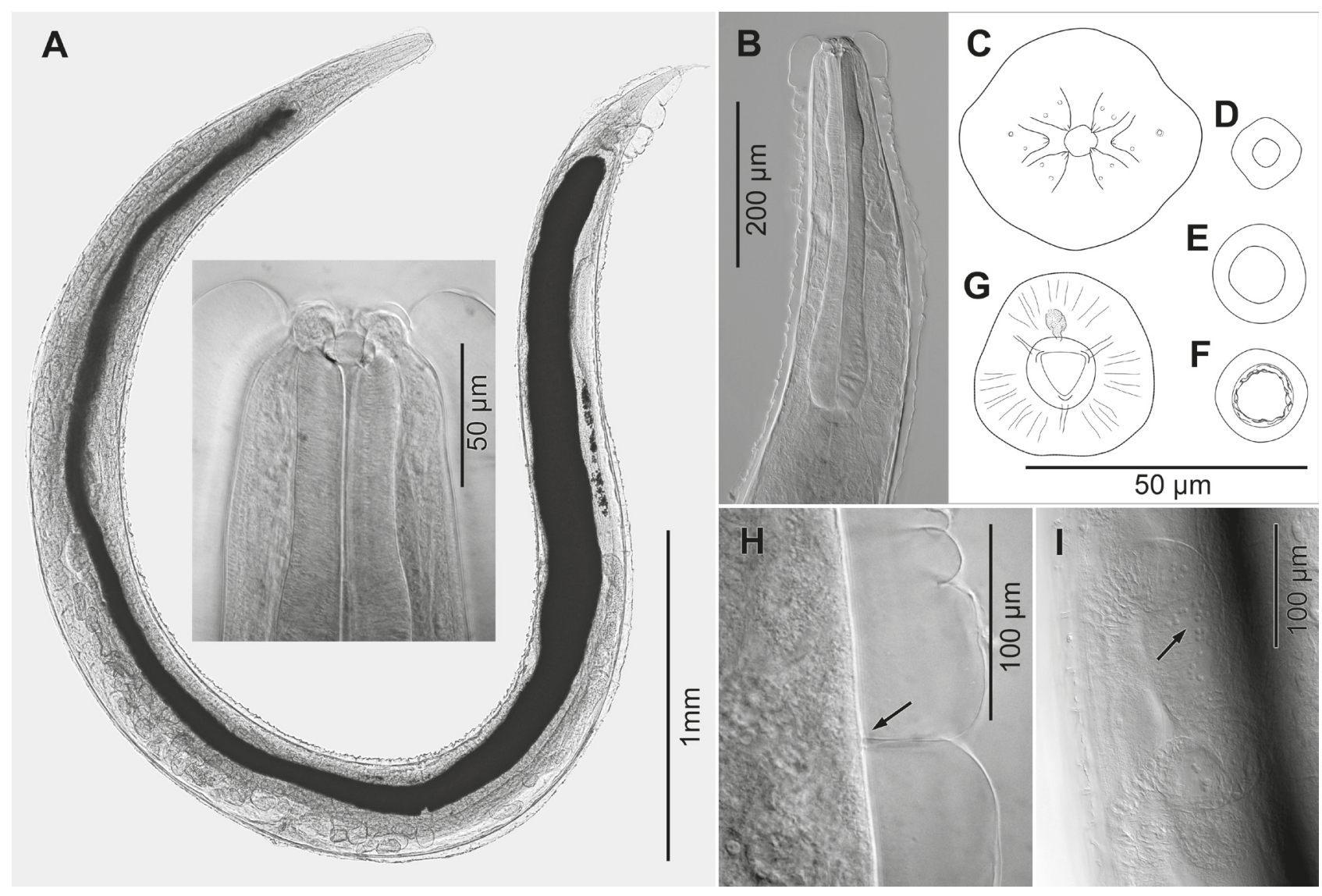

Fig. 3. Rhabdias fuelleborni Travassos, 1926 from Rhinella marina. A - general view and anterior end (inset); B - anterior part of body, lateral view; $\mathbf{C}$ - anterior extremity, en face view; D - optical section through vestibulum; $\mathbf{E}$ - optical section through anterior segment of buccal capsule; $\mathbf{F}$ - optical section through posterior segment of buccal capsule; $\mathbf{G}$ - optical section through bottom of buccal capsule and apex of oesophagus; $\mathbf{H}$ - section of body wall showing lateral pore (arrow) and duct; $\mathbf{I}$ - oviduct with sperm cells inside (arrow).

search Council-Onderstepoort Veterinary Institute, Onderstepoort, South Africa.

Remarks. Rhabdias androgyna was described by Kloss (1971) based on three specimens from Belém (Pará, Brazil; see below). The diagnosis of the species was rather brief, merely postulating its resemblance to $R$. pseudosphaerocephala Kuzmin, Tkach et Brooks, 2007 (cited as R. sphaerocephala Goodey, 1924) in possessing a prominent cuticular swelling at the anterior end, and differentiating it from $R$. fuelleborni by its more slender oesophagus and shorter tail. On the other hand, the division of the cephalic cuticular inflation into an inner and outer layer, and the characteristic shape of the anterior end (presence of shoulder-like broadening) in $R$. androgyna are clearly illustrated in figs. 4a and 12 in Kloss (1971).

By these characters, the present specimens corresponded to those described by Kloss (1971) as $R$. androgyna. The type specimens in Kloss (1971) were characterised by the following measurements: body 9.4-13.4 mm long, oesophagus $577-618$ long (4.3-6.6\% of body length), tail 330-412 long (2.8-3.7\% of body length), and vulva at $5.0-6.4 \mathrm{~mm}$ from anterior end, or at $48-56 \%$ of body length. The specimens examined in the present study correspond well to those studied by Kloss (1971), but have a slightly longer oesophagus, occupying $4.7-8.0 \%$ of the body length.
The conspicuous structure of the cephalic cuticular inflation, the shape of the anterior part of the body, as well as the wide and shallow buccal capsule (average buccal ratio 0.36 ) with serrated lumen in apical view, the rounded and very prominent anterior dilatation of the oesophagus, and the presence of an additional posterior dilatation anterior to the oesophageal bulb are distinctive morphological characters of $R$. androgyna. Kloss (1971) did not illustrate an apical view nor described the lip structure of $R$. androgyna. In the present paper, we provide detail on this important morphological character for the first time.

The occurrence of $R$. androgyna in French Guiana is a new locality record.

Rhabdias fuelleborni Travassos, 1926

Fig. 3

Description [based on 4 specimens; measurements are given as the range for 3 complete and 1 incomplete (anterior part only) specimens]: Body elongated, wider in midregion, gradually tapering toward extremities (Fig. 3A). Anterior end rounded, posterior end pointed. Body length 6.2-7.0 mm, body width 150-160 at oesophago-intestinal junction, 283-302 at vulva. Cuticle inflated along entire body, inflation more pronounced in anterior and posterior parts. Cephalic inflation short, 99-144 wide, not distinctly separated from cuticular inflation along body (Fig. 3B). In 
caudal region, inflation reaching level of phasmids posteriorly. Lateral pores and ducts present (Fig. 3H).

Anterior extremity with slight constriction at level of oesophageal apex (Fig. 3A, inset), and 4 low, rounded subapical elevations of body wall (Fig. 3C). Oral opening rounded. Six lips present. Submedian lips close to edge of oral opening, lateral lips somewhat smaller, situated at some distance from oral opening (Fig. 3C). Each submedian lip bearing one prominent internal labial papilla and two minute external labial papillae. Lateral lips with one internal and one external labial papilla each. Amphidial openings round, situated at base of lateral lips, each surrounded by circular elevation of body wall. Vestibulum 9-10 deep, prominent, cylindrical, with narrow lumen (Fig. 3A, inset, D). Buccal capsule doliiform, 9 deep and 18-19 wide, depth to width ratio $0.47-0.50$. Lumen of buccal capsule almost cylindrical, 9 wide and 9 long. Buccal capsule walls consisting of anterior segment 4-5 long, with smooth internal surface, and posterior segment 4-5 long, with rough internal surface (Fig. 3E,F). Entrance to oesophageal lumen funnel-shaped in lateral view, triangular with rounded sclerotised corners in apical view (Fig. 3G).

Oesophageal apex rounded, encircling posterior half of buccal capsule (Fig. 3A, inset). Oesophagus club-shaped, with dilatation in anterior half and oval posterior bulb (Fig. 3B). Length of oesophagus $431-441$ or $6.2-7.0 \%$ of body length. Oesophagus width 33-36 at apex, 44-47 at anterior dilatation, 35-37 at nerve ring; bulb 71-73 wide. Nerve ring encircling oesophagus posterior to anterior dilatation, at 163-177 from anterior end. Excretory pore at 203 from anterior end (measured in 1 specimen). Excretory glands indistinct.

Anterior end of intestine narrower than oesophageal bulb, then abruptly widening posteriad. Contents of intestine brownish to black. Rectum narrow, prominently cuticularised, wider in anterior part.

Vulva slightly pre-equatorial; distance from anterior end to vulva $3.1-3.4 \mathrm{~mm}$ or $49.4-49.9 \%$ of total length. Vulvar lips slightly salient. Uteri amphidelphic. Eggs numerous, most eggs containing fully developed larvae, 100-116 $\times 42-53(\mathrm{n}=10$, measured in uteri). Both distal flexures of genital system at posterior part of oviducts. Proximal parts of ovaries far overlapping level of vulva. Testis zones not observed in studied specimens, however, sperm cells present in oviduct of one specimen (Fig. 3I).

Tail conical, gradually tapering, 313-345 long (4.7-5.4\% of body length), tail tip pointed and lacking cuticular inflation (Fig. 3A)

H o st: Rhinella marina (Linnaeus) (Bufonidae); collected during 10 April 2012.

L o c a 1 i t y: Wetland in the capital city Cayenne, French Guiana, $04^{\circ} 53^{\prime} 55.7^{\prime \prime} \mathrm{N} ; 52^{\circ} 20^{\prime} 15.2^{\prime \prime} \mathrm{W}$.

Site of infection: Lungs.

Prevalence and intensity of infection: Five specimens from a single host examined.

Deposition of specimens: Four specimens (S/2014/9) deposited in the NCAH.
Remarks. Two species that are morphologically close have been reported from Bufonidae and some Leptodactylidae in South America: R. fuelleborni and R. elegans (see Kloss 1974, González and Hamann 2008). According to Kloss (1974), R. elegans is generally smaller than $R$. fuelleborni and has a smaller buccal capsule (inside measurements): $7 \times 9 \mu \mathrm{m} v s 9 \times 9 \mu \mathrm{m}$, correspondingly. The original descriptions of both $R$. fuelleborni and $R$. elegans offer no information on lip structure. However, González and Hamann (2008) mentioned the presence of 6 small lips in $R$. fuelleborni compared to the absence of distinct lips in R. elegans. Rhabdias elegans has a body length of 4.6-9.5 mm (after Gutiérrez 1945) or 4.7-10.3 mm (after Kloss 1971). Judging by this character, the current specimens, 6.2-7.0 $\mathrm{mm}$ long, are closer to $R$. elegans than to R. fuelleborni, with a body length of 10-12 mm (after Travassos 1926) or 6.6-16.3 mm (after Kloss 1971).

However, based on the dimension of the buccal capsule lumen $(9 \times 9 \mu \mathrm{m})$ and the presence of 6 distinct lips, we assign them to $R$. fuelleborni. Furthermore, similar to the present specimens, the position of the vulva is slightly preequatorial in R. fuelleborni (see Travassos 1926). Rhabdias elegans has been reported mostly from the southern parts of South America, i.e. from southern Brazil, Paraguay, Uruguay and Argentina (Gutiérrez 1945, Kloss 1974, González and Hamann 2008). The only record of this species from Mexico (Goldberg et al. 2002) may be a misidentification (Martínez-Salazar and León-Règagnon 2007) and needs confirmation. Rhabdias fuelleborni has a wider distribution and has been recorded from a vast area, including the aforementioned countries and northern Brazil (Kloss 1974, Vicente et al. 1990, Martínez-Salazar and León-Règagnon, 2007, González and Hamann 2008). These differences in the distribution range of the two species were also taken into consideration in the identification of the present specimens from French Guiana.

\section{Rhabdias sp.}

Fig. 4

Description (based on a single specimen): Body slender, elongated (Fig. 4A), $6.2 \mathrm{~mm}$ long. Body cuticle almost evenly inflated along entire body, narrow, except for anterior end bearing prominent spherical cephalic inflation. Cephalic cuticular inflation 165 wide, distinctly separated from inflated cuticle of body (Fig. 4B). Anterior end with rounded dilatation at level of anterior part of oesophagus, posterior to level of buccal capsule (Fig. 4B). Body width 82 at anterior end (including dilatation), 156 at oesophagointestinal junction, 222 at vulva. Apparently, 6 lips present around oral opening (head structures not examined in apical view). Vestibulum 10 deep. Buccal capsule 11 deep and 18 wide (depth to width ratio 0.61 ), doliiform, with cylindrical lumen. Buccal capsule walls consisting of anterior and posterior segments 6 and 5 long, correspondingly.

Oesophagus with rounded apex, distinct dilatation in anterior part and egg-shaped, elongated bulb. Length of oesophagus 534 , or $8.6 \%$ of body length. Width of 


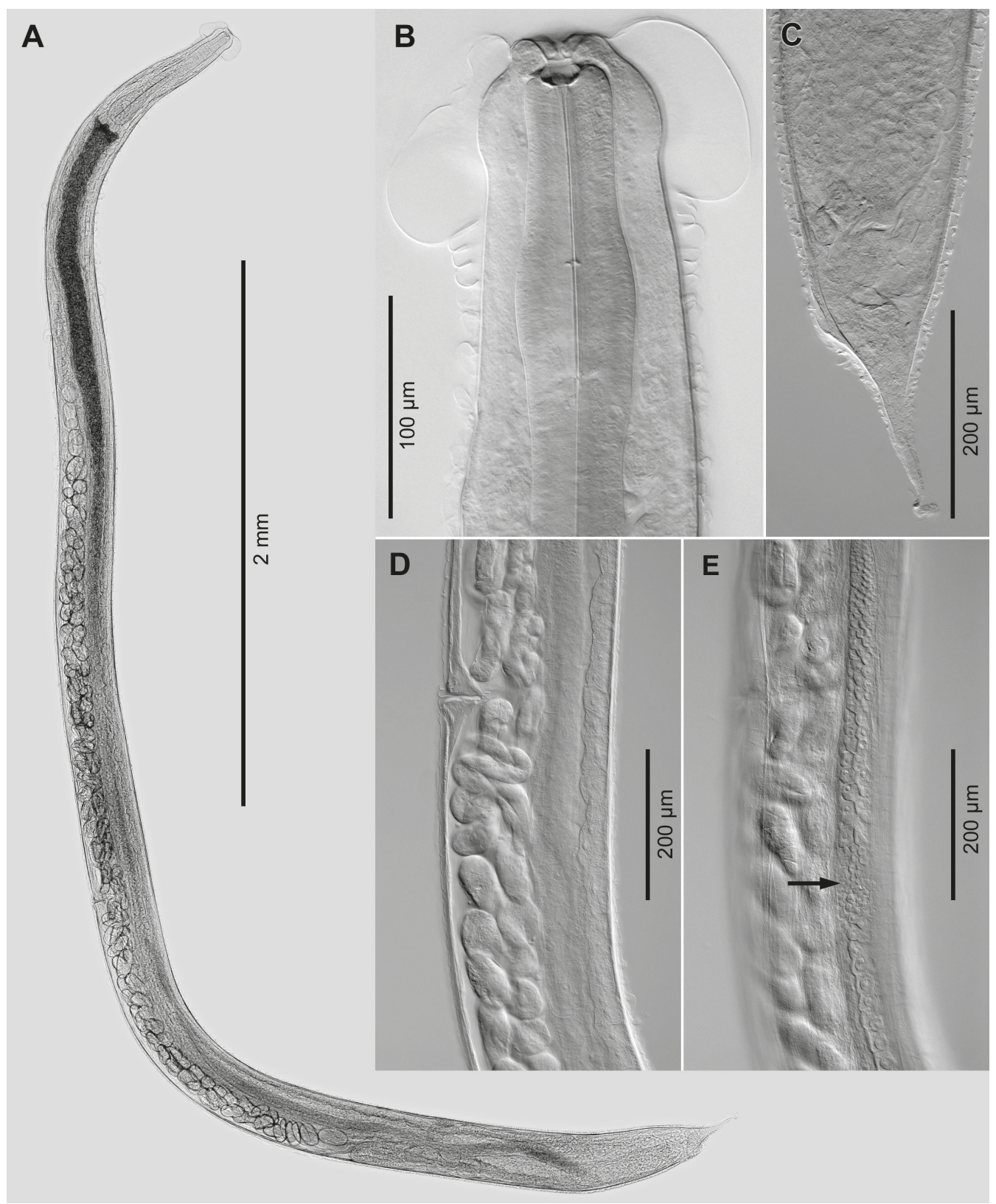

Fig. 4. Rhabdias sp. from Pristimantis chiastonotus. A - general view; $\mathbf{B}$ - anterior end, lateral view; $\mathbf{C}$ - caudal region, lateral view; $\mathbf{D}$ - region of vulva, lateral view; $\mathbf{E}$ - posterior syngonium with testis zone (arrow).

oesophagus 40 at apex, 54 at anterior dilatation, 41 at nerve ring; bulb 87 wide. Anterior end of intestine wider than oesophageal bulb and surrounding its posterior end (Fig. 4A). Nerve ring situated at 180, excretory pore at 226 from anterior extremity.

Vulva postequatorial, situated at $3.4 \mathrm{~mm}$ from anterior end (55\% of body length). Vulval lips slightly salient (Fig. 4D). Uteri amphidelphic, tubular, containing eggs arranged in 2-3 rows, some eggs near vagina with fully developed embryos. Egg size 93-112 × 42-58 $(\mathrm{n}=10$; measured in uteri). Ovaries overlapping level of vulva. Testis zone observed in posterior ovary, somewhat posterior to level of vulva (Fig. 4E).

Tail 208 long (3.3\% of body length), abruptly narrowing in anterior part, gradually tapering in posterior part (Fig. 4C). Phasmids situated at 58 from tail tip.
Host: Pristimantis chiastonotus (Lynch et Hoogmoed) (Craugastoridae); collected during 17 April 2014.

L o cality: Parare camp site, Nouragues National Reserve, French Guiana, $04^{\circ} 02^{\prime} 16.7^{\prime \prime} \mathrm{N}$; 5240'22.6"W.

Site of infection: Lungs.

Prevalence and intensity of infection: One specimen from a single host examined.

Deposition of specimens: One specimen (S/2014/3) deposited in the NCAH.

Remarks. The present specimen of Rhabdias sp. appears to differ from all known species of the genus in Neotropical amphibians. In possessing a globular cephalic cuticular inflation, it is close to $R$. pseudosphaerocephala and $R$. androgyna (see Kloss 1971, present study). Rhabdias pseudosphaerocephala differs, however, from Rhab- 
dias sp. by having a comparatively shorter oesophagus (4.4-6.5\% vs $8.6 \%$ of body length), a less pronounced anterior dilatation of the oesophagus, a narrower oesophageal bulb, and a longer tail (3.7-5.0\% vs 3.3\% of body length) (Kuzmin et al. 2007). Rhabdias androgyna can be distinguished from Rhabdias sp. by the shape of its buccal capsule, the absence of a posterior segment of the buccal capsule, a smaller buccal capsule ratio, and a cephalic inflation that is not simple but divided into an outer and inner layer.

In two species of Rhabdias the body itself shows a pronounced globular swelling in the head region, similar to that seen in the present specimen: $R$. sphaerocephala from Bufo bufo (Linnaeus) (syn. B. vulgaris Laurenti) (Bufonidae) in England, and $R$. ohlerae Junker, Lhermitte-Vallarino et Bain, 2010 from Leptopelis brevirostris (Werner) (Arthroleptidae) in Cameroon. However, in both these species the constriction that sets off the bulbous cephalic swelling from the remainder of the body is more pronounced and the oesophagus is shorter [6.6-7.5\% of body length, calculations based on maximum and minimum values given by Goodey (1924), for $R$. sphaerocephala, and $6.9 \%$ of body length for $R$. ohlerae]; in addition, the tail is shorter in $R$. ohlerae (4.2\% of body length) (Goodey 1924, Junker et al. 2010).

In parasitising a host from the genus Pristimantis Jiménez de la Espada, Rhabdias sp. is close to R. tobagoensis Moravec et Kaiser, 1995, described from Pristimantis cf. terraebolivaris (Rivero) (syn. Eleutherodactylus cf. terraebolivaris Rivero) on Tobago Island (Moravec and Kaiser 1995). This species differs from Rhabdias sp. in the absence of a distinct cephalic cuticular inflation, a shorter buccal capsule (6-9 $\mu \mathrm{m}$ vs $11 \mu \mathrm{m})$, a wider body (maximum body width 408-476 $\mu \mathrm{m}$ vs $222 \mu \mathrm{m}$ ), longer tail and shorter oesophagus.

We conclude that the current specimen belongs to an as yet undescribed species of Rhabdias. It would, however, not be reasonable to describe a new taxon based on a single specimen only, and we thus prefer to leave the specimen unnamed until additional material for a comprehensive description becomes available.

\section{DISCUSSION}

The two nominal Rhabdias species, $R$. androgyna and $R$. fuelleborni, whose descriptions were updated in the present study, belong to a group of Rhabdias occurring in bufonid hosts in South America, mainly Brazil (Kloss 1971, 1974). Rhabdias androgyna was originally described from a host in Belém (Pará, Brazil) recorded as 'Bufo typhonius' Schneider, but likely belonging to Rhi. margaritifera (Laurenti). We found this species in a related host, Rhi. cf. margaritifera, in French Guiana. Presumably, R. androgyna is a specific parasite of at least a part of the Rhi. margaritifera complex of species. Presently, the latter is considered as comprising at least 15 species belonging to several phylogenetic lineages (Ávila et al. 2010); of these, Rhi. lescurei Fouquet, Gaucher, Blanc et Velez-Rodriguez, Rhi. margaritifera and Rhi. martyi Fouquet, Gaucher, Blanc et VelezRodriguez have been recorded from French Guiana (Fouquet et al. 2007). According to our unpublished data, some species of this group may harbour Rhabdias parasites other than $R$. androgyna. The relationships of Rhabdias parasites with their hosts from the Rhi. margaritifera group may be a subject of separate studies in future.

The following is a list of Rhabdias species parasitising amphibians in the Neotropical Realm, including updated data on their host and geographic range. It is noteworthy that not all parasite records were accompanied by detailed morphological studies. Especially with regard to species of Rhabdias whose original descriptions were somewhat perfunctory, their presence in new hosts and localities might need confirmation, once updated descriptions are available.

- R. alabialis Kuzmin, Tkach et Brooks, 2007 from Rhinella marina (Linnaeus) [syn. Bufo marinus (Linnaeus)] (type host), Scinax boulengeri (Cope) and Smilisca baudinii (Duméril et Bibron) (Hylidae) in Costa Rica (Kuzmin et al. 2007, Bursey and Brooks 2010).

- R. androgyna Kloss, 1971 from hosts identified as 'Bufo typhonius (Linnaeus)' (type host), but most likely representing what is currently considered the Rhinella margaritifera species group (Fouquet et al. 2007, Frost 2014), in Brazil (type locality) (Kloss 1971); from Proceratophrys appendiculata (Günther) (Odontophrynidae) in Brazil (Boquimpani-Freitas et al. 2001); from Rhi. margaritifera in Guyana (McAllister et al. 2010); from Rhi. cf. margaritifera in French Guiana (present paper).

- R. breviensis Nascimento, Gonçalves, Melo, Giese, Furtado et Santos, 2013 from Leptodactylus petersii (Steindachner) (type host) and L. macrosternum Miranda-Ribeiro (Leptodactylidae) in Brazil (Nascimento et al. 2013).

- R. elegans Gutiérrez, 1945 from Rhinella arenarum (Hensel) (syn. Bufo arenarum Hensel) (type host) in Argentina (type locality), Paraguay and Uruguay (Gutiérrez 1945, Kloss 1971); from Rhi. rubescens (Lutz) (syn. B. rufus Garman) in Brazil (Kloss 1971); from Odontophrynus americanus (Duméril et Bibron) (Odontophrynidae) in Argentina (Gonzáles and Hamann 2009); from Leptodactylus melanonotus (Hallowell) in Mexico (Goldberg et al. 2002), however, the identity of this Rhabdias species might need confirmation (MartínezSalazar et al. 2009); from the lizard Anolis chrysolepis Duméril et Bibron (syn. Anolis nitens Wagler) (Dactyloidae) in Guyana (McAllister et al. 2010); however, this is an unusual host association and the identification might need confirmation. Lists of additional hosts were compiled by Gonzáles and Hamann (2009) and McAllister et al. (2010).

- R. fuelleborni Travassos, 1926 from Rhinella marina (type host), Rhi. icterica (Spix) (syn. Bufo marinus ictericus Müller) and Rhi. schneideri (Werner) (syn. B. m. paracnemis Müller et Hellmich) in Brazil (type locality) (Travassos 1926, Kloss 1971); from Rhi. ma- 
rina, Smilisca cyanosticta (Smith) and Lithobates vaillanti (Brocchi) (syn. Rana vaillanti Brocchi) (Ranidae) in Mexico (Goldberg et al. 2002); from Rhi. marina in French Guiana (present paper).

- R. hermaphrodita Kloss, 1971 from Rhinella crucifer (Wied-Neuwied) (syn. Bufo crucifer Wied) in Brazil (Kloss 1971).

- R. kuzmini Martínez-Salazar et León-Règagnon, 2007 from Incilius occidentalis (Camerano) (syn. Bufo occidentalis Camerano) (Bufonidae) in Mexico (MartínezSalazar and León-Règagnon 2007).

- R. manantlanensis Martínez-Salazar, 2008 from Craugastor occidentalis (Taylor) (Craugastoridae) in Mexico (Martínez-Salazar 2008).

- R. mucronata Schuurmans-Stekhoven, 1952 in Leptodactylus bolivianus (Boulenger) (syn. L. ocellatus Girard) in Argentina (Schuurmans-Stekhoven 1952); adults unknown and considered a species inquirenda (Bursey et al. 2003, Martínez-Salazar et al. 2009, 2013).

- R. paraensis Santos, Melo, Nascimento, Nascimento, Giese et Furtado, 2011 from Rhinella marina in Brazil (Santos et al. 2011).

- $\boldsymbol{R}$. peninsularis Martínez-Salazar, Falcón-Ordaz, González-Bernal, Parra-Olea et Pérez-Ponce de León, 2013 from Pseudacris hypochondriaca (Hallowell) (Hylidae) in Mexico (Martínez-Salazar et al. 2013).

- R. pseudosphaerocephala Kuzmin, Tkach et Brooks, 2007 from Rhinella marina (type host) in Nicaragua (type locality) and Costa Rica; from Engystompos pustulosus (Cope) (Leptodactylidae) and Litobathes vaillanti in Mexico (Kuzmin et al. 2007, Bursey et Brooks 2010). Specimens originally identified as "Rhabdias sphaerocephala Goodey, 1924" were listed from Rhi. marina in Mexico, Costa Rica, Bermuda islands and Amazonia, and from Rhi. schneideri in Brazil (see Kloss 1971, 1974, Kuzmin et al. 2007).

- R. savagei Bursey et Goldberg, 2005 from Rana sp., Litobathes forreri (Boulenger), L. vaillanti, L. warszewitschii (Schmidt), Craugastor crassidigitus (Taylor), C. gollmeri (Peters), C. melanostictus (Cope), C. taurus (Taylor), Pristimantis caryophyllaceus (Barbour) (syn. Eleutherodactylus caryophyllaceus Dunn) (Craugastoridae), Engystompos pustulosus and Leptodactylus fragilis (Brocchi) in Costa Rica (Bursey and Goldberg 2005, Bursey and Brooks 2010).

- R. tobagoensis Moravec et Kaiser, 1995 from Pristimantis cf. terraebolivaris on Tobago (Moravec and Kaiser 1995); from Dendropsophus microcephalus (Cope) (syn. Hyla microcephala Cope) (Hylidae) in Mexico (Goldberg et al. 2002), but the identity of this Rhabdias species might need confirmation (Martínez-Salazar et al. 2009); from the lizard Anolis uniformis (Cope) (Dactyloidae) in southern Mexico (Cabrera-Guzmán and Garrido-Olvera 2014), however, this is an unusual host association and the identification might need confirmation.

- R. truncata Schuurmans Stekhoven, 1952 from Telmatobius schreiteri Vellard (Telmatobiidae) in Argentina (Schuurmans Stekhoven 1952); adults unknown and considered a species inquirenda (Bursey et al. 2003, Martínez-Salazar et al. 2009, 2013).

- Rhabdias sp. from Scinax staufferi (Cope) in Mexico (Martínez-Salazar et al. 2009).

-Rhabdias sp. from Pristimantis chiastonotus in Guyana (present paper).

In the present description of $R$. androgyna, we emphasise the specific structure of its cephalic cuticular inflation consisting of two layers, the shape and structure of the buccal capsule being much wider than long, and not separated into anterior and posterior segments, as well as the specific shape of the oesophagus, with a very distinct anterior dilatation and an additional dilatation anterior to the bulb. It is important to note that these features were also observed in an immature individual of $R$. androgyna. Moreover, the size of the buccal capsule was similar in the immature individual $(8 \mu \mathrm{m} \times 24 \mu \mathrm{m})$ and gravid specimens $(7-9 \mu \mathrm{m} \times$ $19-27 \mu \mathrm{m})$, and may thus be used as a metrical diagnostic character.

Rhabdias fuelleborni is one of five species parasitic in toads from the Rhi. marina group of species, the remaining four being $R$. elegans, $R$. hermaphrodita, $R$. pseudosphaerocephala and $R$. paraensis (see Kloss 1971, 1974, Santos et al. 2011). These nematodes are rather similar morphologically and were differentiated primarily based on metrical characters related to their body length (Kloss 1974). Such characters, however, may overlap in related species, and their validity as diagnostic characters is doubtful (Baker 1978). Therefore, additional qualitative characters seem to be important for the adequate differentiation among the Rhabdias species within the Rhi. marina group. In the present study, we give a detailed account of the morphology of the anterior end of $R$. fuelleborni, which may help in the reliable identification of this species: the presence of six lips that are almost equal in shape and size, the division of the buccal capsule into anterior and posterior segments with differently structured walls. In future, similar studies of the remaining species of this group may add differential characters to their diagnoses.

The presence of two segments in the buccal capsule, observed in $R$. fuelleborni and Rhabdias sp. in the present study, has previously been reported in a number of species of Rhabdias, mostly parasites of reptiles (LhermitteVallarino et al. 2009a,b, 2010, Tkach et al. 2011), but also in some species from amphibians (Junker et al. 2010). On the other hand, $R$. androgyna obviously lacks such a divi- 
sion of the buccal capsule wall, and the fine structure of the buccal capsule in other Neotropical Rhabdias spp. is still to be investigated.

The lateral pores and ducts were studied in detail in $R$. paraensis by Santos et al. (2011), using SEM and histological methods. Lateral ducts in $R$. androgyna and $R$. fuelleborni could be observed under the light microscope in specimens with a dorsoventral orientation on the slide (Figs. 2B, 3H). These or similar structures were reported in some species of Rhabdias outside the Neotropical Realm (Baker 1987, Junker et al. 2010, Tkach et al. 2011), as well as in some species from other rhabdiasid genera: Kurilonema Szczerbak et Sharpilo, 1969 and Pneumonema Johnston, 1916 (Ballantyne 1986, Kuzmin and Tkach 2011). Presumably, the presence of lateral pores in Rhabdiasidae has a wider distribution than is presently known.

The hermaphroditism of all three Rhabdias species observed in the present study is evidenced by the presence of regions of spermatogenesis in the ovaries (syngonia), and sperm cells in the oviducts. Regions of spermatogenesis, testis zones after Runey et al. (1978), are usually located between the ovarial synapsis and growth zones, where the smaller and loosely arranged male gametes interrupt the regular pattern formed by the densely packed oocytes. Tes- tis zones have been reported in a number of Rhabdias species, suggesting that hermaphroditism is characteristic for this genus. In some species, however, testis zones were not found and this led to conclusions on their parthenogenesis (Lhermitte-Vallarino and Bain 2004). In R. androgyna, we observed testis zones in some of the specimens only and always in one syngonium (more often in the posterior one), but not in both. We, therefore, consider that the absence of testis zones in some specimens of Rhabdias spp. does not constitute unambiguous evidence of their parthenogenesis.

The Neotropical Realm is the region with the highest amphibian species richness worldwide (Duellman 1999). This said, a comparatively small amount of Rhabdias species are currently known from the Neotropics (16 out of more than 70 comprising the world fauna), indicating that far more species are yet to be discovered.

Acknowledgements. This work was partially supported by a grant of the National Research Foundation, South Africa, to one of the authors (KJ). Any opinion, finding and conclusion or recommendation expressed in this material is that of the authors and the NRF does not accept any liability in this regard. Microscopic studies were done using the equipment of the Centre of collective use of scientific equipment 'Animalia' (Institute of Zoology, NAS of Ukraine).

\section{REFERENCES}

Anderson R.C. (Ed.) 2000: Nematode Parasites of Vertebrates. Their Development and Transmission. Second Edition. CABI Publishing, Wallingford, $650 \mathrm{pp}$.

Ávila R.W., Pansonato A., Strüssmann C. 2010: A new species of the Rhinella margaritifera group (Anura: Bufonidae) from Brazilian Pantanal. Zootaxa 2339: 57-68.

BAKER M.R. 1978: Morphology and taxonomy of Rhabdias spp. (Nematoda: Rhabdiasidae) from reptiles and amphibians of southern Ontario. Can. J. Zool. 56: 2127-2141.

BAKeR M.R. 1987: Rhabdias collaris n. sp. (Nematoda: Rhabdiasidae) from frogs of Tanzania. Syst. Parasitol. 9: 199-201.

Ballantyne R.J. 1986: Pneumonema tiliquae (Nematoda: Rhabdiasidae): a reappraisal. In: M. Cremin, C. Dobson and D.A. Moorhouse (Eds.), Parasite Lives. Papers on Parasites, Their Hosts and Their Assocoations. To Honour J.F.A. Sprent. University of Queensland Press, St. Lucia, London, New York, pp. 41-55.

Boquimpani-Freitas L., Vrcibradic D., Vicente J.J, Bursey C.R., Rocha C.F.D., Van Sluys M. 2001: Helminths of the horned leaf frog, Proceratophrys appendiculata, from southeastern Brazil. J. Helminthol. 75: 233-236.

Bursey C.R., Brooks D.R. 2010: Nematode parasites of 41 anuran species from the Area de Conservación Guanacaste, Costa Rica. Comp. Parasitol. 77: 221-231.

Bursey C.R., Goldberg S.R. 2005: New species of Oswaldocruzia (Nematoda: Molineoidae), new species of Rhabdias (Nematoda: Rhabdiasidae), and other helminths in Rana cf. forreri (Anura: Ranidae) from Costa Rica. J. Parasitol. 91: 600-605.

Bursey C.R., Goldberg S.R., Telford S.R. Jr. 2003: Rhabdias anolis n. sp. (Nematoda: Rhabdiasidae) from the lizard, Anolis frenatus (Sauria: Polychrotidae), from Panama. J. Parasitol. 89: 113-117.

Cabrera-Guzmán E., Garrido-Olvera L. 2014: Helminth parasites of the lesser scaly anole, Anolis uniformis (Squamata: Dactyloidae), from Los Tuxtlas, Southern Mexico: evidence of diet and habitat use. South Am. J. Herpetol. 9: 183-189.
Duellman W.E. (Ed.) 1999: Patterns of Distribution of Amphibians: A Global Perspective. Johns Hopkins University Press, Baltimore and London, $633 \mathrm{pp}$.

Fouquet A., Gaucher P., Blanc M., Velez-Rodriguez C.M. 2007: Description of two new species of Rhinella (Anura: Bufonidae) from the lowlands of the Guiana shield. Zootaxa 1663: 17-32

Frost D.R. (Ed.) 2014: Amphibian Species of the World: an online reference. Version 6.0. Electronic Database, http://research. amnh.org/herpetology/amphibia/index.php, American Museum of Natural History, New York, 10/2014.

Goldberg S.R., Bursey C.R., Salgado-Maldonado G., BÁEz R., CAÑEdA C. 2002. Helminth parasites of six species of anurans from Los Tuxtlas and Catemaco Lake, Veracruz, Mexico. Southwest. Nat. 47: 293-299.

GonzÁlez C.E., Hamann M.I. 2008: Nematode parasites of two anuran species Rhinella schneideri (Bufonidae) and Scinax acuminatus (Hylidae) from Corrientes, Argentina. Rev. Biol. Trop. 56: 2147-2161.

González C.E., Hamann M.I. 2009: First report of nematodes in the common lesser escuerzo Odontophrynus americanus (Duméril and Bibron, 1841) (Amphibia: Cycloramphidae) from Corrientes, Argentina. Comp. Parasitol. 76: 122-126.

Goodey T. 1924: Two new species of the nematode genus Rhabdias. J. Helminthol. 2: 203-208.

GutiérRez R.O. 1945 : Contribución al Conicimiento de los Nematodes Parasitos de Anfibios Argentinos. Tesis del Museo de La Plata 8: 37 pp.

Junker K., Lhermitte-Vallarino N., Barbuto M., Ineich I., WANJi S., BAIn O. 2010: New species of Rhabdias (Nematoda: Rhabdiasidae) from Afrotropical anurans, including molecular evidence and notes on biology. Folia Parasitol. 57: 47-61.

KLoss G.R. 1971: Alguns Rhabdias de Bufo no Brasil. Pap. Avulsos Zool. (São Paulo) 24: 1-52.

KLoss G.R. 1974: Rhabdias (Nematoda, Rhabditoidea) from the marinus group of Bufo. A study of sibling species. Arq. Zool. (São Paulo) 25: 61-120. 
Kuzmin Y. 2013: Review of Rhabdiasidae (Nematoda) from the Holarctic. Zootaxa 3639: 1-76.

Kuzmin Y., Tкасн V.V. 2011: Description of a new species of Kurilonema (Nematoda: Rhabdiasidae) from lungs of the skink Sphenomorphus abdictus aquilonius (Reptilia: Squamata: Scincidae) in the Philippines. J. Parasitol. 97: 506-512.

Kuzmin Y., Ткасн V.V. 2014: Rhabdias. World Wide Web electronic publication, http://izan.kiev.ua/ppages/rhabdias, 11/2014.

Kuzmin Y., Tкасн V.V., Brooks D.R. 2007: Two new species of Rhabdias (Nematoda: Rhabdiasidae) from the marine toad, Bufo marinus (L.) (Lissamphibia: Anura: Bufonidae) in Central America. J. Parasitol. 93: 159-165.

Lhermitte-Vallarino N., Bain O. 2004: Morphological and biological study of Rhabdias spp. (Nematoda) from African chameleons with description of a new species. Parasite 11: 15-31.

Lhermitte-Vallarino N., Barbuto M., Junker K., Boistel R., INEICh I., Wanji S., Bain O. 2009a: Rhabdias rhampholeonis $\mathrm{n}$. sp. and R. mariauxi n. sp. (Nematoda, Rhabdiasoidea), first lung worms from leaf chameleons: description, molecular evidence and notes on biology. Parasitol. Int. 58: 375-383.

Lhermitte-Vallarino N., Junker K., Bain O. 2009b: Reappraisal of the specific status of Rhabdias (Nematoda) from Malagasy chameleons in the Paris Museum collection. Parasite 16: 111-123.

Lhermitte-Vallarino N., Barbuto M., Junker K., Boistel R., BAIN O. 2010: Rhabdias (Nematoda: Rhabdiasidae) from Chamaeleonidae (Sauria): two new species from Trioceros ellioti in east Africa and one from Brookesia superciliaris in Madagascar. Parasite 17: 91-105.

Martínez-Salazar E.A. 2008: A new rhabdiasid species from Craugastor occidentalis (Anura: Brachycephalidae) from Sierra de Manantlán, Jalisco, Mexico. Rev. Mex. Biodiv. 79: 81-89.

Martínez-Salazar E.A., Falcón-Ordaz J., GonzálezBernal E., Parra-Olea G., Pérez-Ponce de León G. 2013: Helminth parasites of Pseudacris hypochondriaca (Anura: Hylidae) from Baja California, Mexico, with the description of two new species of nematodes. J. Parasitol. 99: 1077-1085.

Martínez-Salazar E.A., León-Règagnon V. 2007: New species of Rhabdias (Nematoda: Rhabdiasidae) from Bufo occidentalis (Anura: Bufonidae) from Sierra Madre del Sur, Mexico. J. Parasitol. 93: 1171-1177.
Martínez-Salazar E.A., Pérez-Ponce de León G., Parra Olea G. 2009: Primer registro del género Rhabdias (Nematoda: Rhabdiasidae), endoparásito de Scinax staufferi (Anura: Hylidae) en México. Rev. Mex. Biodiv. 80: 861-865.

McAllister C.T., Bursey C.R., Freed P.S. 2010: Helminth parasites of herpetofauna from the Rupunini District, southwestern Guyana. Comp. Parasitol. 77: 184-201.

Moravec F., Kaiser H. 1995: Helminth parasites from West Indian frogs, with descriptions of two new species. Carib. J. Sci. 31: $252-268$.

Nascimento L.C., Gonçalves E.C., Melo F.T., Giese E.G., Furtado A.P., Santos J. 2013: Description of Rhabdias breviensis n. sp. (Rhabditoidea: Rhabdiasidae) in two Neotropical frog species. Syst. Parasitol. 86: 69-75.

Runey W.M., Runey G.L., Lauter F. 1978: Gametogenesis and fertilization in Rhabdias ranae Walton 1929. I. The parasitic hermaphrodite. J. Parasitol. 64: 1008-1014.

Santos J.N., Melo F.T.V., Nascimento L.C.S., Nascimento D.E.B., Giese E.G., Furtado A.P. 2011: Rhabdias paraensis sp. nov.: a parasite of the lungs of Rhinella marina (Amphibia: Bufonidae) from Brazilian Amazonia. Mem. Inst. Oswaldo Cruz 106: 433-440.

Schuurmans Stekhoven J.H. Jr. 1952: Nematodos parasitarios de anfibios, pájaros y mamíferos de la República Argentina. Acta Zoológica Lilloana del Instituto "Miguel Lillo" 10: 315-400.

Travassos L. 1926: Entwicklung des Rhabdias fülleborni $\mathrm{n}$. sp. Arch. Schiffs Tropen-Hyg. 30: 594-602.

Tкасн V.V., Kuzmin Y., Brown R.M. 2011: Rhabdias mcguirei sp. nov. (Nematoda, Rhabdiasidae) from the flying lizard, Draco spilopterus (Squamata, Agamidae) of the northern Philippines. Acta Parasitol. 56: 406-411.

Tкасн V.V., Kuzmin Y., Snyder S.D. 2014: Molecular insight into systematics, host associations, life cycles and geographic distribution of the nematode family Rhabdiasidae. Int. J. Parasitol. 44: 273-284.

Travassos L. 1926: Entwicklung des Rhabdias fülleborni $\mathrm{n} . \mathrm{sp}$. Arch. Schiffs Trop. Hyg. 30: 594-602.

Uetz P., Hošek J. 2015: The Reptile Database. Electronic Database, http://www.reptile-database.org, 02/2015.

Vicente J.J., Rordrigues H.O., Gomes D.C., Pinto R.M. 1990: Nematóides do Brasil. Parte II: Nematóides de anfíbios. Rev. Brasil. Zool. 7: 549-626.
Received 4 February 2015

Accepted 19 March 2015

Published online 4 June 2015

Recive 4 Febra

Cite this article as: Kuzmin Y., du Preez L.H., Junker K. 2015: Some nematodes of the genus Rhabdias Stiles et Hassall, 1905

(Nematoda: Rhabdiasidae) parasitising amphibians in French Guiana. Folia Parasitol. 62: 031. 